\title{
Malignant melanoma of the conjunctiva
}

\author{
AMRESH GHOPDAR \\ West of England Eye Infirmary, Exeter
}

\section{Case report}

A 65-year-old woman presented at the Outpatients Department of the West of England Eye Infirmary on January 8, 1970, complaining of a pigmented mass at the corneo-scleral junction of the right eye of uncertain duration. On questioning she remembered having previously had a small brownish spot at about 4 to $5 \mathrm{~mm}$. away from the limbus.

In the past she had had some degree of hyperthyroidism and hypertension, but was free from symptoms and not receiving any treatment.

\section{Examination}

There was an elliptical pigmented lesion $6 \times 3 \mathrm{~mm}$. and raised by approximately $\mathrm{I} \mathrm{mm}$. from the surface at the temporal side of the limbus of the right eye. The lesion extended over the surface of the cornea, almost reaching to the outer margin of the pupil; there was also a slight extension laterally from the limbus to the bulbar conjunctiva. A large blood vessel was feeding the tumour from the lateral canthus (Fig. I).

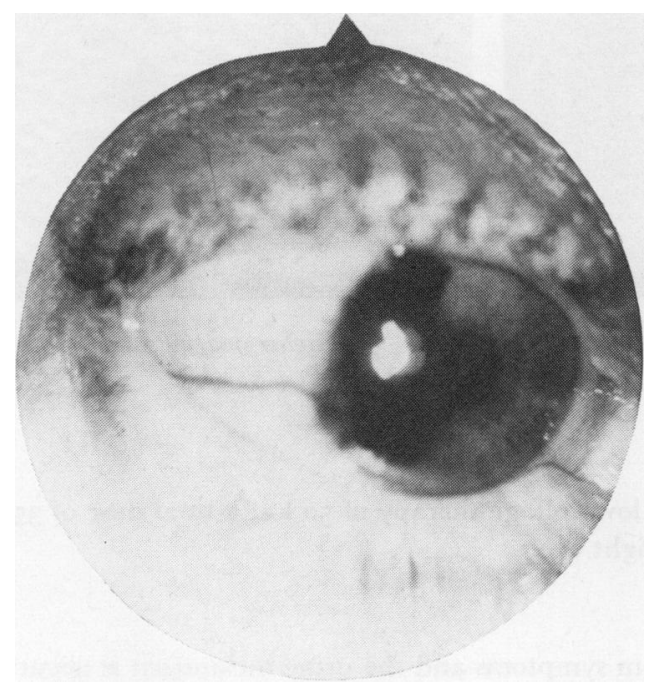

FIG. I Malignant melanoma at the limbus in the right eye. Note large feeding vessel

The visual acuity was $6 / 6$ in the right eye, with $+2.5 \mathrm{D}$ sph., $+0.25 \mathrm{D}$ cyl., axis $90^{\circ}$, and $6 / 4$ in the left eye, with $+2.25 \mathrm{D}$ sph., $+0.25 \mathrm{D}$ cyl., axis $180^{\circ}$.

Biomicroscopy showed a heavily pigmented mass at the limbus extending over the cornea and conjunctiva. Gonioscopy revealed wide open angles and no deposit of pigment. Ophthalmoscopy showed no abnormality.

She was admitted to hospital, where a detailed physical examination revealed no evidence of any secondary infiltration. There were no glandular swellings, no enlargement of liver or spleen, and no pigmented lesions of the skin. 


\section{Laboratory investigations}

A peripheral blood film and liver function tests were all within normal limits.

Chest $x$ ray showed no other abnormalities except a moderate dilatation of the left ventricle.

Urine melanogen was positive preoperatively and became negative postoperatively.

\section{Treatment}

A wide excision of the mass was undertaken under general anaesthesia. The large feeding vessel was cauterized first. Next a wider area of conjunctiva was excised by means of a diathermy needle. The part attached to the cornea was separated with a Castroviejo razor-blade knife and a good cleavage line was obtained. The tumour was removed completely with little difficulty. It was not necessary to remove the corneal tissue deeper than the epithelium. The bare excised area was covered by a conjunctival flap.

\section{Histopathology report}

Malignant melanoma of spindle cell type with numerous melanophages (Figs 2 and 3 ).

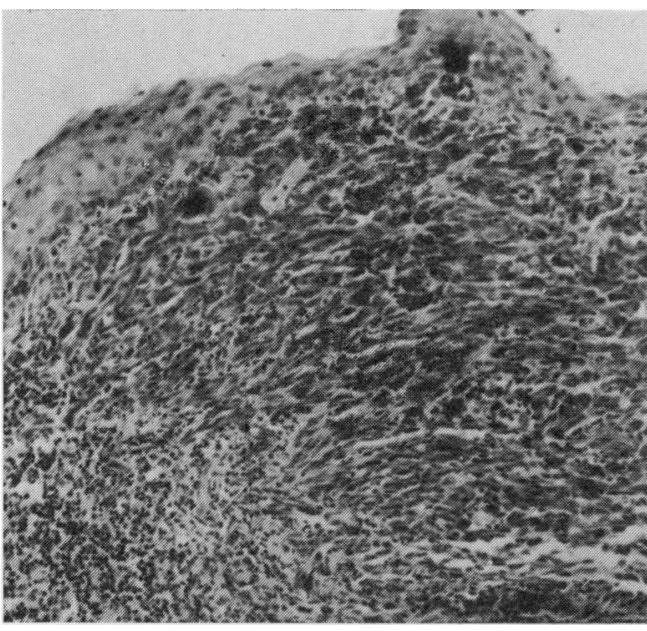

FIG. 2 Section of excised melanoma showing spindle cells $\times 7 \cdot 5$

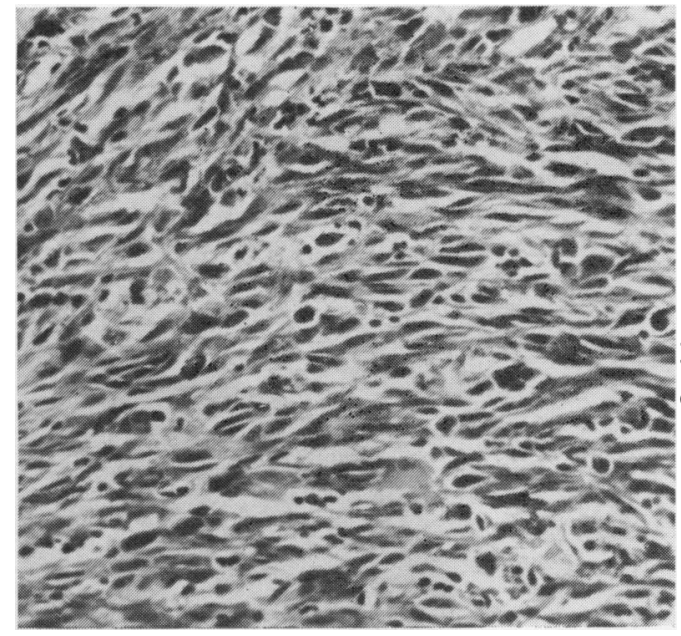

FIG. 3 Higher magnification showing spindle cells $\times 30$

\section{Radiotherapy}

It was decided that she ought to have low voltage therapy of $50 \mathrm{kv}$; a total dose of $3500 \mathrm{r}$ in 9 days was given to the excision area of the right eye.

Result

The patient is now completely free from symptoms and the urine melanogen is negative.

\section{Discussion}

Benign naevi are not uncommonly seen in the conjunctival sac, whereas malignant melanomata of the conjunctiva, especially the spindle cell type, are infrequent (Hogan and Zimmerman, r962; Reese, 1963; Jay, 1964, 1965).

In this case it seems that a benign naevus had later undergone malignant change. This leads to the question whether all conjunctival naevi should be excised routinely at an early stage. 


\section{Summary}

A case of conjunctival malignant melanoma in a woman aged 65 years with positive urine melanogen was treated by means of wide excision and low voltage radiotherapy. The urine melanogen became negative after treatment.

My thanks are due to Mr. G. L. Cantrell, consultant ophthalmologist, and to Dr. R. A. Caldwell, consultant histopathologist, for their help.

\section{References}

hogan, M. J., and zimmerman, L. E. (1962) “Ophthalmic Pathology”, 2nd ed., p. 259. Saunders, Philadelphia

JAY, B. (1964) Trans. ophthal. Soc. U.K., 84, 339

- —— (1965) Brit. F. Ophthal., 49, 169

REESE, A. B. (1963) "Tumors of the Eye", 2nd ed., p. 335. Harper and Row, New York 